\title{
The experience of stroke survivors three months after being discharged home: A phenomenological investigation
}

European Journal of Cardiovascular Nursing 2015, Vol. 14(2) 162-169

(C) The European Society of Cardiology 2014 Reprints and permissions: sagepub.co.uk/journalsPermissions.nav DOI: $10.1|77 /| 4745$ | 5 | | 4522886 cnu.sagepub.com

\author{
Silvio Simeone', Serenella Savini', Marlene Z Cohen², Rosaria \\ Alvaro' and Ercole Vellone'
}

\begin{abstract}
Background: Stroke is the leading cause of disability in adults, and has a significant impact on individuals, families, and society. Returning home after a stroke represents a challenging experience for patients who struggle to adapt to their new life conditions. Although many studies have been conducted on stroke survivors, few studies have focused on the lived experience of patients at three months after they came home after rehabilitation.

Aims: The aim of this study was to describe the experience of stroke survivors three months after being discharged home from rehabilitation hospitals.

Method: A phenomenological methodology was used to conduct the study. Participants were enrolled from rehabilitation hospitals in the cities of Rome and Naples. Interviews were conducted at the patients' house and data were analysed with a phenomenological approach

Findings: Fifteen stroke survivors were interviewed (mean age 70 years; 12 males). Five themes emerged from the phenomenological analysis of the interviews and the field notes: deeply changed life, vivid memory of the acute phase of the stroke, slowed lives, relief after recovering from stroke, being a burden for family members.

Conclusions: The results of this study give an overview of the experience of stroke survivors three months after being discharged home. From a clinical perspective, health care providers need to provide more interventions to help survivors to cope better with life changes and encourage them to adapt to daily life limitations caused by stroke. Also, health care providers should improve support provided to family members of stroke patients.
\end{abstract}

\section{Keywords}

Stroke, stroke survivors, lived experiences, phenomenology

Date received: 27 June 20I3; revised: 16 January 20I4; accepted: 17 January 2014

\section{Introduction}

Stroke is the second leading cause of death in the Western world, preceded only by heart disease and cancer. ${ }^{1}$ About 5.5 million people die from stroke every year worldwide. ${ }^{2}$ The prevalence and the incidence of stroke increase exponentially with age, peaking in people older than 85 years, with $75 \%$ of strokes occurring in those over 65 years old. 3,4 In Europe and in Italy the prevalence of stroke ranges from 4.6-7.3 per 1000, and the annual incidence ranges between 7.5-10.1 per 1000 for people over 65 years old. ${ }^{3}$

Stroke is the leading cause of disability in the adult population: one year after a stroke about one-third of patients are entirely dependent due to high levels of residual disability. ${ }^{5}$ This results in a significant impact on individuals, families and health care costs. ${ }^{6,7}$

Returning home after a stroke is a challenging experience for patients who struggle to adapt to their new life conditions because of physical disabilities, stress, depression,

IUniversity of Rome Tor Vergata, Rome, Italy

2University of Nebraska Medical Center, Omaha, NE, USA

Corresponding author:

Ercole Vellone, Department of Biomedicine and Prevention, University of Rome Tor Vergata, Via Monpellier, I, 00133 Rome, Italy.

Email: ercole.vellone@uniroma2.it 
cognitive impairment and reduced quality of life..$^{8-10}$ Although many studies have been conducted on stroke survivors' experiences, few studies have focused on the lived experience of patients when they return home. ${ }^{11-16}$ In addition, although many advances have been made in stroke rehabilitation which may have an impact on how stroke is perceived by survivors, ${ }^{17-19}$ few studies have been conducted in the last decade on these perceptions. ${ }^{11-13}$ Existing research has been conducted with several qualitative methodologies and sometimes focused on the specific experience of patients, for example, transition from hospital to home and the consequences of stroke, ${ }^{11}$ the experiences related to basic care needs during in-hospital stay (e.g. elimination, personal hygiene, eating), ${ }^{20}$ the experience of eating difficulties, ${ }^{21}$ apraxia, ${ }^{22}$ depression, ${ }^{23}$ returning to work, ${ }^{24}$ and sometimes these studies were gender specific, enrolling only female people. ${ }^{15}$ In addition, investigators ${ }^{12,14,16}$ have included patients who differed in terms of time from their discharge home, which may limit the understanding of stroke survivors' experience. In fact, stroke survivors physical and psychological status changes over time ${ }^{16}$ and this might influence the meaning which patients attribute to their condition. Rachpukdee et al. ${ }^{25}$ recently found that predictors of quality of life after stroke change between one month and three months from when patients are discharged home. In fact soon after the stroke, generally within the first month, patients are still focused on physical recovery and do not pay attention to other important aspects of life such as, for example, family relationships, that generally emerge three months after patients are discharged home..$^{25}$ A precise and consistent description of the lived experience of stroke survivors at this specific time (three months after stroke survivors are discharged home) is lacking in the literature but may be usefully known in order to provide better care for patients who experience changing conditions over time. Therefore, the aim of this study was to describe the lived experience of stroke survivors three months after being discharged home from a rehabilitation hospital.

\section{Methods}

\section{Design, participants and setting}

A methodology based on phenomenology was used to conduct this study, ${ }^{26}$ combining features of descriptive (Husserlian) and interpretive phenomenology (Gadamerian); This methodology has been used in several studies. ${ }^{27-29}$ Phenomenological methodology was chosen to conduct this study because it allows a deeper understanding of peoples' lived experience as well as an investigation of the meaning people attribute to an experience. In fact, according to the phenomenological approach that guided this study, ${ }^{26}$ 'Understanding patients' experiences may guide nurses to interact in ways that may differ from people who lack that understanding' and 'The meanings that patients attribute to their experiences help create the needs they have and how these needs can best be met' (p.4). Also, we chose phenomenological methodology to conduct this study because, as discussed by Goldberg, ${ }^{30}$ the recovery from a stroke is rooted in patients' lived experience, including patients' perceptions and expectations, which have a deep phenomenological connection.

Participants interviewed in this study were selected from those involved in a larger ongoing Italian multi-site longitudinal study aimed at studying quality of life in patients after stroke. In the longitudinal study patients are enrolled at discharge from rehabilitation hospitals and then are followed up for one year. Quantitative data were collected regarding patients' quality of life when patients were discharged and then every three months. To be enrolled in the multi-site longitudinal study participants met the following inclusion criteria: having a first stroke; being discharged from a rehabilitation hospital three months before; having no comorbidity with other motor disorders (e.g. amyotrophic lateral sclerosis, Parkinson's disease, multiple sclerosis, neuropathies); no aphasia, clinical dementia, cancer or severe organ failure, such as renal failure or heart failure. Participants in this phenomenological study were consecutively selected from the 80 patients surveyed at three months from discharge in the longitudinal study. Interviews with those who agreed to participate in this phenomenological study continued until data reached saturation with 15 patients: 13 patients were from two rehabilitation hospitals in Rome and two patients were from two other rehabilitation hospitals in Naples.

\section{Data collection and analysis}

Before data collection each investigator involved in the study performed 'bracketing' that requires each researcher to write all pre-understandings, prejudices and assumptions about the phenomenon. ${ }^{26}$ In Cohen et al.'s methodology ${ }^{26}$ this is called the Critical Reflection Technique and helps investigators to be rigorous in analysis. In fact, phenomenological methodologies use an interpretative approach where researchers' own perspectives and the historical contexts can make the accuracy of analysis contingent or somewhat tentative. ${ }^{26}$ However, when researchers perform 'bracketing', which is writing their assumptions and beliefs about the phenomenon, before data collection and analysis, they are more alert to subtle prejudices. ${ }^{26}$ Bracketing enhances the credibility of the data and analysis by reducing the chance that researchers will introduce their own biases rather than seeing the data from the participants' perspective. After bracketing, all interviews were performed by the first author. This investigator contacted stroke survivors enrolled in the longitudinal study three months after their discharge home and made an appointment for the interview. Interviews were all performed at patients' 
houses. During interviews, the researcher asked participants the open-ended question, 'Please describe your experience during the past three months since you were discharged home'. The use of an open-ended question is required in phenomenological research because it allows participants complete freedom in reporting their experiences. The participants' 'world' becomes the focus of the investigation rather than topics chosen by researchers. ${ }^{31}$ The investigator had a welcoming attitude 27,32 during the interviews, i.e. expressing cordiality and reassurance, not judging patients' storytelling and being serene and smiling to facilitate participants' describing their experience. During and after the interview the investigator took field notes on her own reflections, the setting, environment and patients' body language. When participants seemed not to have anything further to say, the researcher asked them if they had anything more to add. If they did not, the interview ended. Data saturation, that is the sampling to the point at which redundancy of the extracted themes is attained, ${ }^{31}$ was achieved after 15 interviews. All interviews lasted from $30 \mathrm{~min}$ to one hour and were all digitally audiorecorded. The interview was tested with two patients whose data were not included in this analysis. This test was done to allow the investigator who performed the interview to become familiar with the methodology. After each interview the investigator administered the Barthel Index ${ }^{33}$ which is a tool to evaluate patient's autonomy in performing activities of daily living such as mobility, feeding, bathing, toilet using, grooming, transfer, dressing, climbing stairs, bowel and bladder control. The Barthel Index has possible score from $0-100$ with higher scores meaning better independence, and has been widely used in the stroke population. ${ }^{34,35}$

All interviews were transcribed verbatim and the accuracy between the digital audio-recordings and the transcripts was checked. The transcriptions were also translated into English to involve the foreign co-investigator. This approach has been successfully used in prior research, ${ }^{27,32}$

The analysis was performed by each investigator. In the Cohen et al. ${ }^{26}$ methodology, researchers first reads each transcript several time to get a sense of the whole. Then, the researcher re-reads each transcript line by line and starts to uncover a tentative notion of the meaning of an experience and labels passages with theme labels. In doing this the researcher uses a reflective awareness that leads to dialectical examination of parts of the data to better understand the whole. When the whole is understood, different data or the same parts of the data are examined at a deeper level. Passages and themes from an interview are then compared with passages from other interviews.

To establish theme trustworthiness, a comparison of extracted themes was performed and discussed amongst all investigators in order to reach agreement; discussion with the foreign investigator was done by e-mail. Trustworthiness was also enhanced by asking patients to confirm extracted themes. The themes were confirmed by patients prior to writing this article.

\section{Ethical considerations}

Ethical approval was obtained before data collection in each centre where participants were enrolled. Patients also signed an informed consent form after the study was explained to them and before the interview. Participants were assured their data would contain no identifying information, and that they had the right to withdraw from the study at any time.

\section{Findings}

Participants were 70 years old on average (age range 3485). Twelve stroke survivors were male, three were female; 13 patients lived in Rome, two lived in Naples ( $08 \mathrm{AH}$ and $10 \mathrm{AJ}$ ). Level of education was low with 11 of the participants educated only at elementary or middle school level. Eight participants were married and seven were widowed. All, except one patient (13 AM), were retired at the time of the interview. Most of the strokes were ischaemic, nine patients had a stroke in the right hemisphere, six patients in the left. Autonomy measured by the Barthel Index ${ }^{33}$ was $77 / 100$ on average which means that patient were quite functionally independent. With the exception of two patients (04 AD and $09 \mathrm{AI}$ ), all patients lived with family (Table 1).

Five themes emerged from the analysis of the interviews and the field notes: deeply changed life, vivid memory of the acute phase of the stroke, slowed lives, relief after recovering from stroke, being a burden for family members.

\section{Deeply changed life}

The most frequent theme that emerged from participants' descriptions of their lived experience was 'deeply changed life'. Not only had life changed for survivors but it was deeply changed. Participants were aware that their stroke had forever changed their lives both physically and psychologically. Stroke sequels had changed their life patterns: life now appeared less secure and more precarious. One participant reported: 'Stroke is an event that marks you, that changes your life. It seems that your life becomes precarious. You become aware that nothing is safe' (12 $\mathrm{AL})$. Another participant also reported:

Well, the stroke is an event that marks you, that changes your life. All seems reduced to a kind of precarious sensation. Shortly, you realise that nothing is certain anymore, no one has certainty. But when you have been affected by stroke you realise that in a few minutes you can leave everything and everyone. (07 AG) 
Table I. Sociodemographic and clinical characteristics of the sample $(n=15)$.

\begin{tabular}{|c|c|c|c|c|c|c|c|c|c|c|}
\hline Code & Initials & Age & Gender & Education & $\begin{array}{l}\text { Marital } \\
\text { status }\end{array}$ & Employment & $\begin{array}{l}\text { Type of } \\
\text { stroke }\end{array}$ & $\begin{array}{l}\text { Stroke } \\
\text { site }\end{array}$ & $\begin{array}{l}\text { Barthel } \\
\text { Index }\end{array}$ & $\begin{array}{l}\text { Living } \\
\text { alone }\end{array}$ \\
\hline OI & $\mathrm{AA}$ & 60 & $M$ & $M$ & $M$ & $\mathrm{R}$ & I & $\mathrm{R}$ & 40 & No \\
\hline 02 & $A B$ & 75 & $M$ & $E$ & $M$ & $\mathrm{R}$ & $\mathrm{H}$ & $\mathrm{R}$ & 100 & No \\
\hline 03 & $A C$ & 68 & $M$ & $E$ & W & $\mathrm{R}$ & I & $\mathrm{L}$ & 70 & No \\
\hline 04 & $A D$ & 78 & $M$ & $E$ & W & $\mathrm{R}$ & I & $\mathrm{L}$ & 90 & Yes \\
\hline 05 & $\mathrm{AE}$ & 64 & $M$ & $\mathrm{H}$ & $M$ & $\mathrm{R}$ & $\mathrm{H}$ & $\mathrm{R}$ & 80 & No \\
\hline 06 & $\mathrm{AF}$ & 69 & $M$ & $M$ & W & $\mathrm{R}$ & I & $\mathrm{R}$ & 75 & No \\
\hline 07 & $A G$ & 63 & $M$ & $\mathrm{H}$ & $M$ & $\mathrm{R}$ & 1 & $\mathrm{R}$ & 80 & No \\
\hline 08 & $\mathrm{AH}$ & 77 & $\mathrm{~F}$ & $E$ & W & $\mathrm{R}$ & I & $\mathrm{R}$ & 40 & No \\
\hline 09 & $\mathrm{Al}$ & 65 & $M$ & $M$ & $M$ & $\mathrm{R}$ & I & $\mathrm{R}$ & 100 & Yes \\
\hline 10 & AJ & 85 & $\mathrm{~F}$ & $E$ & W & $\mathrm{R}$ & I & $\mathrm{L}$ & 75 & No \\
\hline II & AK & 83 & $M$ & $E$ & W & $\mathrm{R}$ & I & $\mathrm{L}$ & 100 & No \\
\hline 12 & $\mathrm{AL}$ & 63 & $M$ & $M$ & $M$ & $\mathrm{R}$ & I & $\mathrm{L}$ & 50 & No \\
\hline 13 & $A M$ & 34 & $M$ & $M$ & $M$ & $E$ & I & $\mathrm{R}$ & 90 & No \\
\hline 14 & AN & 85 & $M$ & $\mathrm{H}$ & W & $\mathrm{R}$ & I & $\mathrm{L}$ & 100 & No \\
\hline 15 & $\mathrm{AO}$ & 83 & $\mathrm{~F}$ & $\mathrm{H}$ & $M$ & $\mathrm{R}$ & I & $\mathrm{R}$ & 70 & No \\
\hline
\end{tabular}

Notes: All initials are fictitious. Education (E: elementary school; M: middle school; H: high school); Marital status (M: married; W: widowed); Employment (R: retired; E: employed); Type of stroke (I: ischaemic; H: haemorrhagic); Stroke site (R: right hemisphere; L: left hemisphere).

Barthel Index measures independence: higher score means higher independence and vice versa (possible range: 0-100).

Another participant added: 'My life has changed, I am no longer able to stand alone: before [the stroke] I was able to shave by myself, now I need help, as well as to eat, go for a walk' (09 AI). This patient lived alone, but received care from his son's family who lived downstairs in the same house.

Participants noted that even their homes needed to be changed, to be adapted to their disability. A participant explained: 'When I came back home my family had to rearrange the house for me to facilitate my movements with the wheelchair' (01 AA).

\section{Vivid memory of the acute phase of the stroke}

Many patients had very strong and powerful memories of the acute phase of the stroke event. During the interview they vividly described the physical sensations they felt as the stroke began and during the following days. Patients clearly remembered the feeling of fear that something strange was happening. And this fear was still present in participants. A patient described:

At the minimum physical effort the mind runs always and remember those moments, that feeling of helplessness, of death. Since then [before stroke] I used to have a much quieter life, but not anymore. Many times my mind goes to those moments of fear of dying, fear of being immobile. Yes, life goes on but your mind is marked by the stroke. (02 AB)

When he talked about this experience, this participant's facial expression showed his fear. Another participant reported: 'My mind often remembers when the stroke happened. I felt fear, fear of dying' (13 AM).

\section{Slowed lives}

Many participants noted that their stroke had slowed down their lives: they related this to body movements, to cognitive and decision making processes. A participant noted:

I can move both hands but one [the unaffected hand] is at $100 \%$ and the other one is at $90 \%$. This other hand is like it gets tired more quickly. So, I feel slowed down. Also when I walk I feel slowed down. (15 AO)

During this report the patient showed the movement of both arms to let the interviewer see the differences between the two arms. Another participant said: 'I do almost all the same things I used to do before the stroke, but slowly. I walk slower. Sometimes it also seems to me that I speak slower: I think words but they come out slowly' (04 AD). Also another participant reported: 'I have no major limitations, although I note my uncertainty in doing things, as if I am in slow motion, I am slow to walk and sometimes even in articulating my thoughts' (07 AG).

\section{Relief after recovering from stroke}

During the interviews patients very often reported that they felt relieved as they recovered and as they gained more physical independence. This theme was common among participants, even those who still had some limitations. The feelings of relief were associated with their physical and cognitive recovery even after minimal recovery. One survivor told us: 'Fortunately my conditions were not changed for a long time. Now I have the same life that I had before. I'm healthy now, as you can see, I can move my hand, arm, 
foot, leg' (03 AC). In showing the possible movements of the limbs, he smiled, showing his happiness in observing the movements that he could do. This description is consistent with this patient's Barthel Index score since with a score of 70 he could move his upper and lower limbs but was not completely independent to move from his bed to a chair or to climb stairs. Another participant reported:

The important thing is, to me, that now everything is back to normal. Now I am able to walk, to go to the bathroom alone. At first it was a tragedy: at the beginning the catheter, then the diaper. Now, thanks to God, those things are the past. (07 AG)

Another participant explained: 'I had the fear that I would become useless. So I thought it was better to be thrown out of the window or die soon. But now I am healed, luckily, and everything is better than before' (10 AJ). When describing this change, this participant showed a serene facial expression. Another participant said: 'Luckily I have had a quick recovery, a good recovery. There are still some steps forward that I need to make, but I am optimistic' (13 AM).

\section{Being a burden to family members}

Another theme extracted from the interviews was the feeling of being a burden to family members. In fact, patients were aware of, and felt guilty for, the discomfort they caused to their family. This was heightened because none of them received support from the National Health Service at home. One patient even felt guilty about her daughter's divorce. She said:

I see the life of my family members now revolves around my life. You see the lives of people around you being upset because of you. It is true that at a certain age children have to take care of their parents, but this disrupts their lives. They have two jobs, their job and me. (12 AL)

This patient appeared heart broken by this situation and cried during the interview. Another patient said:

Do you see the condition in which I put my son? I forced my son to bounce among work, home, his family, and me. My son seems like a yo-yo attached to the rope running back and forth, poor man! Now he has started to become nervous about silly things. (05 AE)

Another also said: 'I'm a burden for them, I need help for almost everything and I see that my life has a huge impact on their lives [family members]' (O8 AH).

\section{Discussion}

The aim of this study was to describe the lived experience of stroke survivors three months after being discharged home in order to improve our understanding of what it means to stroke survivors to go back to their usual life. Themes that emerged from the phenomenological analysis showed that patients experienced a deep change in their lives, had a vivid memory of the acute phase of the stroke, felt that their lives had been slowed down, felt relieved for the recovery but also felt they were a burden for their family members. These findings add a new dimension to the literature because prior studies have not been specifically focused on the whole lived experience of stroke survivors during the first three months after being discharged home. Understanding stroke survivors' lived experience during this time is important since it is generally three months after being at home that patients 'first' have a comprehensive experience of the stroke. Prior to this time, they are more likely to be focused only on the meaning of physical disability, and only later can they also focus on the meaning of other aspects of daily life and family interactions ${ }^{25}$

Other authors have also investigated the lived experiences of stroke survivors with qualitative methods but we found only two published studies in the last 12 years that used a phenomenological perspective to uncover the meaning of the 'whole' experience of stroke. ${ }^{15,16}$ The first study ${ }^{15}$ was conducted with five female survivors one year after the stroke and the investigators found the overarching theme of transformations which was interwoven with six other themes, which were dawning awareness of self as disabled, life and suffering through inexorable losses, quest for self, adaptation to change, existential reestablishment of self, reconciliation and re-engagement. These themes are similar to the experiences our stroke survivors described in the themes of a deeply changed life and slowed lives. Similarities are interesting despite difference in the two studies. Hilton's study ${ }^{15}$ was conducted 12 years ago and enrolled only women who had survived from stroke one year before. In the other phenomenological study ${ }^{16}$ the themes were: body experiences, coping, and altered life. The results of this study are also somewhat similar to our findings in relation to the themes of a deeply changed life and slowed lives, since changes and slowness in our participants sometimes referred to changes of the body. However changes and slowness in other aspects of life were discussed. Also, in Pallesen's study, ${ }^{16}$ stroke survivors were enrolled five years after their stroke and themes might reflect the chronic results of the stroke disabilities rather than 'first' or initial experiences related to the stroke. Unlike the findings of another earlier phenomenological study ${ }^{36}$ none of our participants reported changes in embodiment: this may be due to the high level of physical functioning of our stroke survivors.

In our interviews, survivors described vivid memories of the acute phase of their stroke and the emotional consequences (fear of dying, fear of being immobile). Other researchers ${ }^{14,37}$ have reported similar results, primarily emphasising that patients feared having another stroke. 
Our findings indicate even stronger fears in the sense that according to the criteria specified in the Diagnostic and statistical manual for mental disorders (DSM-V) ${ }^{38}$ the lived experience of our participants might reflect a posttraumatic stress disorder that quantitative studies have only recently found in stroke survivors. ${ }^{39,40}$ Our participants never mentioned fear of having another stroke. This might result from our participants, even though at risk for another stroke, ${ }^{41,42}$ not being aware of that risk. Perhaps this also relates to the early time at which our participants were interviewed. The need for educational interventions focused on preventing future strokes may be important.

Another theme from the interviews was relief after recovering from stroke. This theme has not been reported in prior studies and might reflect the way in which our participants (who had a mean Barthel Index score of 77/100) were in general quite autonomous even though they were in need of help with some activities of daily living. It was interesting to note that one participant (09 AI) experienced a discrepancy between his reported experience, expressing clear disability in activities of daily living, and his Barthel Index score, which was 100/100. This was not completely a surprise since the ceiling effect of the Barthel Index is reported in the literature ${ }^{43}$ and so patients may have a high score on this measure even though they are not completely independent. However, in general, we noticed that even little improvements in rehabilitation yielded the feeling and perception of having reached a good level of performance. In addition, this emphasises the need for health care providers to understand the patients' view of their abilities and not focus only on 'objective' measures.

The last theme from these interviews was that of being a burden to family members. Stroke has a significant impact on the quality of life in stroke survivors' family members ${ }^{12,44}$ and evidence also shows that caregivers' well-being affects stroke survivors' recovery. ${ }^{45}$ A recent study ${ }^{46}$ found that caregivers' self-esteem, optimism and perceived control influenced depression in stroke survivors. Therefore, health care providers should consider the psychological status of stroke caregivers. Dalvandi et al. ${ }^{12}$ reported the theme of 'life disintegration' where stroke survivors felt as if they were a burden for others and noted that because of the consequences of their stroke they felt they had destroyed the lives of people close to them. However, it is important to note that this theme may reflect that participants of our study did not receive any support from the National Health Service and so most of the care they needed was the responsibility of their family members.

\section{Limitations}

Our study has a number of limitations. First, our participants were mostly males (12 of 15$)$ and this might have influenced the reported experiences. For example, literature reports that female stroke survivors have a worse quality of life than men:8,47 in our study if more females had been involved, more 'negative' themes related to the lived experience of stroke might have been seen, and perhaps the theme related to relief might not have been so prominent. However, women in our study who reported relief linked it with their recovery, so perhaps recovery is more important than gender. Research with a larger group of men and women would be useful to clarify this. Another limitation is that our participants were mostly independent and their lived experience would likely have been different if they were more dependent. Including more participants who had severe limitations, and perhaps even focusing exclusively on more debilitated persons, would be useful to understand their needs.

\section{Conclusion}

This study has provided an overview of the lived experience of stroke survivors three months after being discharged home, and to our knowledge no prior studies have explored the experience of stroke survivors at this specific time. Shyu et al. ${ }^{48}$ emphasised the importance of intervening with stroke survivors even after their physical rehabilitation and our findings might contribute to refining interventions aimed at improving a comprehensive recovery after patients are discharged home.

Results of this study allowed us to uncover the meaning that patients give to the first three months after they return home after a stroke. From a clinical perspective, our findings emphasise the importance of continuing physical and psychological recovery even when patients return home. In fact our participants reported feelings that might affect their recovery such as how they had deeply changed lives, vivid memories of the stroke event, and concerns about being a burden on their families. These findings might be useful for nurses and other health care professionals both in the acute phase of the stroke, in rehabilitation, and particularly in home care settings. In fact, Vincent et al. ${ }^{49}$ showed a gap between the health care professionals' rehabilitation goals and those of stroke survivors: while professionals are more oriented to the physical and cognitive rehabilitation, patients are more focused on the return to their normal life that will result from the rehabilitation. Knowing how patients experience their return to normal life may help professionals provide stroke survivor-centred care. Quantitative studies have found several predictors of patient's quality of life after a stroke $\mathrm{s}^{50,51}$ and have described how quality of life changes over time. ${ }^{25,52}$ Despite this, $40 \%$ of stroke survivors are not satisfied with the care they received..$^{53}$ Fraas $^{54}$ has emphasised that phenomenological studies can offer a comprehensive and holistic approach to study stroke recovery, can facilitate survivors (and caregivers as well) recovery by 
highlighting factors that can promote successful recovery, and can guide clinicians to develop a more effective and holistic treatment, which in turn can improve survivors' active coping style based on their expectations.

Our study explored the lived experience of stroke survivors three months after being discharged home. Future research is needed to investigate the experience of patients over time because the recovery process from stroke is dynamic and unstable. ${ }^{55,56}$ Future research should also take into consideration the lived experience of caregivers since they have an important influence on stroke survivors. ${ }^{57}$

\section{Implications for practice}

- Providers should focus more on stroke survivors' expectations about stroke recovery.

- Providers should help survivors to cope with life changes after stroke.

- Providers should guide survivors on how to adapt their daily life to limitations resulting from the stroke.

- Providers should educate survivors on how to prevent another stroke.

- Providers should improve support to families of stroke patients.

\section{Conflicts of interest}

None declared.

\section{Funding}

This study was funded by the Centre of Excellence for Nursing Scholarship, Rome, Italy.

\section{References}

1. Donnan GA, Fisher M, Macleod M, et al. Stroke. Lancet 2008; 371: 1612-1623.

2. World Health Organization. The atlas of heart disease and stroke, www.who.int/cardiovascular_diseases/resources/ atlas/en/ (2013, accessed 18 June 2013).

3. Di Carlo A, Baldereschi M, Gandolfo C, et al. Stroke in an elderly population: Incidence and impact on survival and daily function. The Italian Longitudinal Study on Aging. Cerebrovasc Dis 2003; 16: 141-150.

4. European Registers of Stroke Investigators, Heuschmann PU, Di Carlo A, et al. Incidence of stroke in Europe at the beginning of the 21 st century. Stroke 2009; 40: 15571563.

5. SPREAD. Ictus cerebrale: Linee guida italiane di prevenzione e trattamento, www.spread.it/files/SPREAD_5_2007_ sintesi.pdf (2007,accessed 18 June 2013).

6. Zorowitz RD, Gillard PJ and Brainin M. Poststroke spasticity: Sequelae and burden on stroke survivors and caregivers. Neurology 2013; 80: S45-S52.

7. Fattore G, Torbica A, Susi A, et al. The social and economic burden of stroke survivors in Italy: A prospective, incidence-based, multi-centre cost of illness study. BMC Neurol 2012; 12:137.

8. Carod-Artal J, Egido JA, Gonzalez JL, et al Quality of life among stroke survivors evaluated 1 year after stroke: Experience of a stroke unit. Stroke 2000; 31:2995-3000.

9. Carod-Artal FJ, Trizotto DS, Coral LF, et al. Determinants of quality of life in Brazilian stroke survivors. J Neurol Sci 2009; 284: 63-68.

10. Cerniauskaite M, Quintas R, Koutsogeorgou E, et al. Quality-of-life and disability in patients with stroke. Am J Phys Med Rehabil 2012; 91: S39-S47.

11. Rittman M, Faircloth C, Boylstein C, et al. The experience of time in the transition from hospital to home following stroke. J Rehabil Res Dev 2004; 41: 259-268.

12. Dalvandi A, Heikkila K, Maddah SS, et al. Life experiences after stroke among Iranian stroke survivors. Int Nurs Rev 2010; 57: 247-253.

13. Donnellan C, Martins A, Conlon A, et al. Mapping patients' experiences after stroke onto a patient-focused intervention framework. Disabil Rehabil 2013; 35: 483-491.

14. Ellis-Hill CS, Payne S and Ward C. Self-body split: Issues of identity in physical recovery following a stroke. Disabil Rehabil 2000; 22: 725-733.

15. Hilton EL. The meaning of stroke in elderly women: A phenomenological investigation. J Gerontol Nurs 2002; 28: 19-26.

16. Pallesen H. Body, coping and self-identity. A qualitative 5-year follow-up study of stroke. Disabil Rehabil 2014; 36 : 232-41.

17. Knecht S, Hesse S and Oster P. Rehabilitation after stroke. Dtsch Arztebl Int 2011; 108: 600-606.

18. Homberg V. [Neurological rehabilitation]. Internist (Berl) 2010; 51: 1248-1253.

19. Rosati G. The place of robotics in post-stroke rehabilitation. Expert Rev Med Devices 2010; 7: 753-758.

20. Kitson AL, Dow C, Calabrese JD, et al. Stroke survivors' experiences of the fundamentals of care: A qualitative analysis. Int J Nurs Stud 2013; 50: 392-403.

21. Klinke ME, Hafsteinsdottir TB, Thorsteinsson B, et al. Living at home with eating difficulties following stroke: A phenomenological study of younger people's experiences. $J$ Clin Nurs 2013; 23: 250-260.

22. Arntzen $\mathrm{C}$ and Elstad I. The bodily experience of apraxia in everyday activities: A phenomenological study. Disabil Rehabil 2013; 35: 63-72.

23. Kouwenhoven SE, Kirkevold M, Engedal K, et al. 'Living a life in shades of grey': Experiencing depressive symptoms in the acute phase after stroke. $J$ Adv Nurs 2012; 68: 17261737.

24. Medin J, Barajas J and Ekberg K. Stroke patients' experiences of return to work. Disabil Rehabil 2006; 28: 10511060 .

25. Rachpukdee S, Howteerakul N, Suwannapong N, et al. Quality of life of stroke survivors: A 3-month follow-up study. J Stroke Cerebrovasc Dis 2013; 22: e70-e78.

26. Cohen MZ, Kahn D and Steeves R. Hermeneutic phenomenological research: A practical guide for nurse researchers. Thousand Oaks, California: Sage, 2000.

27. Vellone E, Piras G, Venturini G, et al. The experience of quality of life for caregivers of people with Alzheimer's 
disease living in Sardinia, Italy. J Transcult Nurs 2012; 23: 46-55.

28. Cohen MZ, Torres-Vigil I, Burbach BE, et al. The meaning of parenteral hydration to family caregivers and patients with advanced cancer receiving hospice care. J Pain Symptom Manage 2012; 43: 855-865.

29. Talucci C, Vellone E, Piras G, et al. The experiences referred to the quality of life in caregivers of patients with Alzheimer's disease living in Lazio and Sardinia: A comparative phenomenological study. Salute e Società 2013; 12: $126-140$.

30. Goldberg G. Medical phenomenology and stroke rehabilitation: An introduction. Top Stroke Rehabil 2011; 18: 1-5.

31. Polit DF and Beck CT. Essentials of nursing research. 8th ed. Philadelphia: Lippincott Williams \& Wilkins, 2014.

32. Vellone E, Piras G, Talucci C, et al. Quality of life for caregivers of people with Alzheimer's disease. J Adv Nurs 2008; 61: 222-231.

33. Mahoney FI and Barthel DW. Functional evaluation: The Barthel Index. Md State Med J 1965; 14: 61-65.

34. Joseph $\mathrm{C}$ and Rhoda A. Activity limitations and factors influencing functional outcome of patients with stroke following rehabilitation at a specialised facility in the Western Cape. Afr Health Sci 2013; 13: 646-654.

35. Hung MC, Hsieh CL, Hwang JS, et al. Estimation of the long-term care needs of stroke patients by integrating functional disability and survival. PLoS One 2013; 8: e75605.

36. Gadow S. Body and self: A dialectic. In: Kestenbaum V, ed. The humanity of the ill: Phenomenological perspectives. Knoxville, Tennessee: University of Knoxville Press; 1982, pp.86-100.

37. Bakas T, Austin JK, Okonkwo KF, et al. Needs, concerns, strategies, and advice of stroke caregivers the first 6 months after discharge. J Neurosci Nurs 2002; 34: 242-251.

38. American Psychiatric Association. Diagnostic and statistical manual of mental disorders. 5th ed. Arlington, Virginia: American Psychiatric Publishing; 2013.

39. Goldfinger JZ, Edmondson D, Kronish IM, et al. Correlates of post-traumatic stress disorder in stroke survivors. J Stroke Cerebrovasc Dis 2014; 23: 1099-1105.

40. Favrole P, Jehel L, Levy P, et al. Frequency and predictors of post-traumatic stress disorder after stroke: A pilot study. J Neurol Sci 2013; 327: 35-40.

41. Go AS, Mozaffarian D, Roger VL, et al. Heart disease and stroke statistics-2013 update: A report from the American Heart Association. Circulation 2013; 127: e6-e245.

42. Armario P and de la Sierra A. Antihypertensive treatment and stroke prevention: Are angiotensin receptor blockers superior to other antihypertensive agents? Ther $A d v$ Cardiovasc Dis 2009; 3: 197-204.

43. Sarker SJ, Rudd AG, Douiri A, et al. Comparison of 2 extended activities of daily living scales with the Barthel
Index and predictors of their outcomes: Cohort study within the South London Stroke Register (SLSR). Stroke 2012; 43: 1362-1369.

44. Ostwald SK, Swank PR and Khan MM. Predictors of functional independence and stress level of stroke survivors at discharge from inpatient rehabilitation. J Cardiovasc Nurs 2008; 23: 371-377.

45. Lui MH, Ross FM and Thompson DR. Supporting family caregivers in stroke care: A review of the evidence for problem solving. Stroke 2005; 36: 2514-2522.

46. Chung M, Bakas T, Plue L, et al. Effects of self-esteem, optimism, and perceived control on depression: Testing dyadic dynamics in stroke survivor-spouse dyads. Paper presented at: International Stroke Conference; 6-8 February 2013, Honolulu, Hawaii.

47. Roth DL, Haley WE, Clay OJ, et al. Race and gender differences in 1-year outcomes for community-dwelling stroke survivors with family caregivers. Stroke 2011; 42: 626-631.

48. Shyu YI, Maa SH, Chen ST, et al. Quality of life among older stroke patients in Taiwan during the first year after discharge. J Clin Nurs 2009; 18: 2320-2328.

49. Vincent C, Deaudelin I, Robichaud L, et al. Rehabilitation needs for older adults with stroke living at home: Perceptions of four populations. BMC Geriatr 2007; 7: 20.

50. Van Bragt PJ, van Ginneken BT, Westendorp T, et al. Predicting outcome in a postacute stroke rehabilitation programme. Int J Rehabil Res 2014; 37: 110-117.

51. Allan LM, Rowan EN, Thomas AJ, et al. Long-term incidence of depression and predictors of depressive symptoms in older stroke survivors. Br J Psychiatry 2013; 203: 453-460.

52. Teoh V, Sims J and Milgrom J. Psychosocial predictors of quality of life in a sample of community-dwelling stroke survivors: A longitudinal study. Top Stroke Rehabil 2009; 16: $157-166$.

53. Tistad M, Tham K, von Koch L, et al. Unfulfilled rehabilitation needs and dissatisfaction with care 12 months after a stroke: An explorative observational study. BMC Neurol 2012; $12: 40$.

54. Fraas MR. Enhancing quality of life for survivors of stroke through phenomenology. Top Stroke Rehabil 2011; 18: 40 46.

55. Dixon G, Thornton EW and Young CA. Perceptions of selfefficacy and rehabilitation among neurologically disabled adults. Clin Rehabil 2007; 21: 230-240.

56. Patel MD, McKevitt C, Lawrence E, et al. Clinical determinants of long-term quality of life after stroke. Age Ageing 2007; 36: 316-322.

57. Godwin KM, Swank PR, Vaeth P, et al. The longitudinal and dyadic effects of mutuality on perceived stress for stroke survivors and their spousal caregivers. Aging Ment Health 2013; 17: 423-431. 